\title{
ÁREAS DE PRESERVAÇÃO PERMANENTE NO NOVO CÓDIGO FLORESTAL NACIONAL: A QUESTÃO DAS MATAS CILIARES
}

William Ferreira da Silva - Universidade Federal de Goiás - Campus Jataí - Departamento de Geografia Rua Riachuelo, 1530 - 75804-077 - Jataí - GO, Brasil, williamjatai@gmail.com

Celso de Carvalho Braga - Instituto Federal de Goiás - Campus Jataí - Coordenação de Geomática

Rua Riachuelo, 2090, 75804-020 - Jataí - GO, Brasil, celsobraga@jatai.ifgoias.edu.br

Vander de Souza Lima - Instituto Federal de Goiás - Campus Jataí, vander@jatai.ifgoias.edu.br

Renato Ferreira da Silva Júnior - Unopar - Pólo Jataí - Gestão Ambiental, Rua Dep. Manoel da Costa Lima, 1006 75800-017 - Jataí - GO, Brasil, renato2007_jti@hotmail.com

\section{RESUMO}

O debate sobre a necessidade de conservação de áreas de vegetação nativa é constante. Diariamente nos deparamos com notícias de ações realizadas por entidades ambientalistas em busca de garantir a proteção de áreas importantes para a manutenção da biodiversidade e de ambientes naturais. Por outro lado, a vocação agrícola presente em nosso país faz com que seja exercida forte pressão sobre áreas onde ainda não há utilização agropecuária para que estas áreas sejam incorporadas ao processo produtivo. Neste cenário, a legislação ambiental brasileira deve servir para disciplinar o uso de áreas e recursos naturais e ao mesmo tempo permitir o crescimento do setor de agropecuária, um dos motores da economia brasileira. As leis que definem as áreas de proteção estão atualmente sendo redefinidas em âmbito nacional (Código Florestal Nacional) e com isto estabelece amplo debate entre ambientalistas e ruralistas, principalmente no que se refere a delimitação de Áreas de Preservação Permanente. O Código Florestal de 1965 estabelece critérios para a delimitação da extensão das matas ciliares com base na largura do espelho d'água e padroniza os valores para todo o território nacional, fato que permite críticas por parte de ruralistas e até mesmo de alguns ambientalistas. O Projeto de Lei que estabelece o novo Código Florestal Nacional coloca como pressupostos à delimitação de matas ciliares, estudos técnicos regionalizados realizados através de Zoneamento Econômico Ecológico, permitindo assim, que os estados criem suas próprias regras de acordo com a realidade das condições naturais e econômicas de cada local.

Palavras-chave: código florestal, matas ciliares, áreas de preservação permanente.

\section{ABSTRACT}

The debate on the need for conservation of areas of native vegetation is constant. Every day we see reports of actions taken by environmental entities seeking to ensure the protection of important areas for the maintenance of biodiversity and natural environments. Moreover, the Brazilian agricultural vocation makes strong pressure on areas, where there are no agricultural use, to be incorporated into the production process. In this scenario, the Brazilian environmental law should serve to discipline the use of areas and natural resources and in the same time allow the growth of the sector of agriculture, one of the engines of the Brazilian economy. The laws that define the areas of protection are currently being redefined at the national level (National Forest Code) and it provides broad debate among environmentalists and rural people, especially as regards the delimitation of areas of permanent preservation. The Forest Code from 1965 establishes criteria for the delineation of the extent of riparian forests on the basis of the width of the mirror of water and standardizes the values for the entire national territory, which allows criticism from the rural people and even some environmentalists. The Law Project which establishes the new National Forest Code places assumptions as to the delineation 
of riparian forests, regional technical studies conducted by Ecological Economic Zoning, which allows that the states establish their own rules in accordance with the reality of the natural and economic conditions of each site.

Key-words: forest code, riparian woodland, areas of permanent preservation.

\section{INTRODUÇÃO}

Atualmenteodebateemtornodadelimitação de Áreas de Preservação Permanente (APPs) e Reservas Legais (RL) tem causado calorosos debates na sociedade brasileira, principalmente envolvendo proprietários rurais, órgãos de proteção ambiental e instituições ambientais. De um lado os proprietários rurais interessados em expandir a utilização de suas terras, de outro as instituições e órgãos ambientalistas interessados em garantir o cumprimento das leis referentes a este assunto.

Neste contexto surgem diversos problemas, dentre eles se destaca a indefinição na interpretação das leis referentes a este assunto. Desde a criação do Código Florestal Brasileiro em 1965, ocorreram diversas mudanças na lei e na forma de interpretação da lei que determina o que é a Área de Preservação Permanente, sendo que as principais polêmicas giram em torno da delimitação da mata ciliar. Os debates se tornaram mais calorosos nos últimos anos em função da reformulação do Código Florestal de Santa Catarina, que admite limites diferentes para a delimitação da mata ciliar em relação ao Código Nacional.

No Congresso Nacional está em tramitação apropostadeformulaçãodonovoCódigoFlorestal Nacional, através do Projeto de Lei 5367/2009. Durante as discussões para a elaboração deste Projeto de Lei, a bancada ruralista enfrenta a bancada ambientalista liderada pelo Partido Verde (PV). As duas bancadas defendem seus pontos de vista a respeito da questão. Ruralistas atestam que se o Código for feito de acordo com a proposta dos ambientalistas, cerca de $73 \%$ do território nacional se tornaria área de reserva, enquanto os ambientalistas atestam que se for reduzida a área de mata ciliar os cursos de água seriam seriamente afetados.

Com base na legislação atual, nas propostas que se apresentam no PL 5367/2009 e nos debates atuais a respeito da questão da delimitação de áreas de preservação permanente, este trabalho pretende trazer à discussão esta importante questão, contribuindo para que haja esclarecimento sobre as possíveis conseqüências em se adotar posicionamentos radicais a este respeito.

\section{MATERIAL E MÉTODOS}

O Brasil possui uma série de leis que versam sobre a questão ambiental. Se aplicadas na íntegra, as questões ambientais no país estariam praticamente solucionadas. No entanto, a aplicação das leis de forma rígida, levaria a inviabilização de diversas atividades econômicas dos mais diversos setores, sendo destaque os setores agrícola e industrial. São incontáveis os casos de indústrias que se instalaram em locais protegidos e que estão operando a décadas no mesmo local. Punir esta empresa com a aplicação literal da lei atual pode não ser a atitude mais justa, visto que em diversos casos, quando da instalação da unidade produtiva o local não era considerado uma área de proteção. No setor agrícola, também existem diversos casos em que o produtor se adapta às exigências de determinadas leis e logo após esta lei é alterada. Por outro lado, ocorrem abusos de oportunistas, que em meio ao emaranhado jurídico, buscam brechas para burlar as leis e maximizar a exploração de recursos naturais no menor tempo possível. O presente trabalho propõe um debate do contexto jurídico atual quanto a delimitação da extensão das matas ciliares. Para tal, foi realizado levantamento bibliográfico sobre a questão e o confronto entre o Código Florestal Nacional (Lei $\mathrm{N}^{\mathrm{o}}$ 4.771, de 15 de setembro de 1965) acrescido de suas alterações através de leis complementares e medidas provisórias, o Código Florestal de Santa Catarina (Lei $\mathrm{N}^{\circ}$ 14.675, de 13 de abril de 
2009) e o Projeto de Lei para a elaboração do novo Código Florestal Nacional (Projeto de Lei 5367/2009), que atualmente tramita no Senado. Além disso, foram confrontados posicionamentos de grupos ambientalistas e ruralistas sobre a questão, através de seus pronunciamentos em documentos, manifestos e reportagens.

\section{RESULTADOS E DISCUSSÃO}

\section{OCódigo Florestal Nacionalé a lei máxima}

que estabelece para todo o território nacional os parâmetros de delimitação de APPs. Esta lei estabelece as condições gerais para a delimitação das áreas de preservação permanente ao longo de cursos de água, ao redor de nascentes e em áreas de relevo com elevada declividade, sem levar em conta as particularidades regionais da estrutura fundiária e das características naturais de solo, relevo, clima e vegetação natural das APPs.

TABELA 1. Comparação entre os Códigos Florestais do Brasil e de Santa Catarina quanto à delimitação de matas ciliares.

\begin{tabular}{|c|c|c|c|}
\hline \multirow{2}{*}{ Localização da APP } & \multirow{2}{*}{\begin{tabular}{|c|}
$\begin{array}{c}\text { Código Florestal } \\
\text { Nacional - } 1965\end{array}$ \\
Qualquer Propriedade \\
\end{tabular}} & \multicolumn{2}{|c|}{ Código Florestal de Santa Catarina - 2009} \\
\hline & & $\begin{array}{l}\text { Propriedades de } \\
\text { até } 50 \text { ha }\end{array}$ & $\begin{array}{c}\text { Propriedades maiores } \\
\text { que } 50 \text { ha }\end{array}$ \\
\hline $\begin{array}{l}\text { Cursos de água com } \\
\text { largura inferior a } 5 \mathrm{~m} \text {. }\end{array}$ & $30 \mathrm{~m}$ & $5 \mathrm{~m}$ & $10 \mathrm{~m}$ \\
\hline $\begin{array}{l}\text { Cursos de água com } \\
\text { largura entre } 5 \mathrm{e} 10 \mathrm{~m} .\end{array}$ & $30 \mathrm{~m}$ & \multicolumn{2}{|c|}{$10 \mathrm{~m}$} \\
\hline $\begin{array}{l}\text { Cursos de água com } \\
\text { largura entre } 10 \text { e } 50 \mathrm{~m} .\end{array}$ & $50 \mathrm{~m}$ & \multicolumn{2}{|c|}{$\begin{array}{c}10 \mathrm{~m} \text { acrescidos de } 50 \% \text { da medida } \\
\text { excedente a } 10 \mathrm{~m}\end{array}$} \\
\hline $\begin{array}{l}\text { Cursos de água com } \\
\text { largura entre } 50 \text { e } 200 \mathrm{~m} .\end{array}$ & $100 \mathrm{~m}$ & \multicolumn{2}{|c|}{$\begin{array}{c}10 \mathrm{~m} \text { acrescidos de } 50 \% \text { da medida } \\
\text { excedente a } 10 \mathrm{~m}\end{array}$} \\
\hline $\begin{array}{l}\text { Cursos de água com } \\
\text { largura entre } 200 \text { e } 600 \mathrm{~m} .\end{array}$ & $200 \mathrm{~m}$ & \multicolumn{2}{|c|}{$\begin{array}{l}10 \mathrm{~m} \text { acrescidos de } 50 \% \text { da medida } \\
\text { excedente a } 10 \mathrm{~m}\end{array}$} \\
\hline $\begin{array}{l}\text { Cursos de água com } \\
\text { largura superior a } 600 \mathrm{~m} .\end{array}$ & $500 \mathrm{~m}$ & \multicolumn{2}{|c|}{$\begin{array}{c}10 \mathrm{~m} \text { acrescidos de } 50 \% \text { da medida } \\
\text { excedente a } 10 \mathrm{~m}\end{array}$} \\
\hline Entorno de nascentes & $50 \mathrm{~m}$ & \multicolumn{2}{|c|}{$10 \mathrm{~m}$} \\
\hline
\end{tabular}

De acordo com o Código Florestal Nacional em vigor atualmente, as unidades federativas tem a possibilidade de elaborar seus códigos florestais desde que não haja redução dos limites estabelecidos pelo Código Florestal Nacional. O recém aprovado Código Florestal de Santa Catarina estabelece limites diferentes para a delimitação das APPs (Tabela 1), além de levar em conta o tamanho da propriedade e permitir em determinados casos a exploração econômica de áreas de preservação permanente, como versa o artigo 115 do código catarinense, onde é colocada a possibilidade de plantio de espécies vegetais frutíferas e medicinais exóticas nas APPs, desde que se respeite algumas condições, como o consorciamento com espécies nativas; a não implicação do corte da vegetação nativa, salvo para manejo sustentável; e a não utilização de fertilizantes ou pesticidas químicos.

O Código Florestal Catarinense está em desacordo com o Código Nacional ao reduzir os limites mínimos para a delimitação das APPs no entorno de nascentes e cursos de água, e ao admitir o uso econômico sustentável destas áreas, sendo portanto, inconstitucional ao desobedecer uma lei federal. No entanto, esta lei se antecipa a aprovação do novo Código Florestal Nacional ao usar da prerrogativa de que os estados passam a ter autonomia para o estabelecimento de parâmetros para a delimitação de áreas de proteção.

Em virtude dos debates atuais a respeito da ineficácia do Código Florestal Brasileiro e de uma necessidade de reformulação desta lei, várias 
questões estão sendo abordadas nos debates entre políticos, pesquisadores, ambientalistas e demais segmentos sociais interessados na questão. Por um lado, a bancada ruralista e a Confederação Nacional da Agricultura (CNA) questionam as bases científicas usadas na lei vigente para a determinação da extensão da mata ciliar, por outro, a bancada ambientalista argumenta que se existem necessidades de mudanças, estas seriam para ampliar a proteção existente atualmente para que se pudesse garantir a manutenção das próximas gerações e o cumprimento de ações por parte do Brasil no atendimento a tratados ambientais internacionais como o Tratado de Quioto.

O primeiro grupo atesta que as condições de solo, clima, relevo, estrutura produtiva e fundiária são bastante diversas no país, e que por isso, as restrições quanto ao uso econômico de áreas próximas a cursos de água e a nascentes devem ser revistas levando em conta critérios científicos e econômicos, uma vez que a OMC (Organização Mundial do Comércio) apresenta sérias restrições a mercadorias de países onde não se cumprem as leis ambientais. Do ponto de vista destes, as leis ambientais não podem ser um impedimento para a expansão da produção agropecuária, deve ocorrer o uso racional dos recursos naturais, inclusive em áreas que sejam consideradas de preservação permanente. Defendem ainda, a descentralização das decisões sobre os limites das Áreas de Preservação Permanente, os órgãos ambientais estaduais e os municipais teriam melhores condições para avaliar a situação em cada local e definir os limites levando em conta as particularidades de cada caso. A bancada ruralista vê na aprovação do Código Florestal de Santa Catarina o futuro para o país, visto que esta lei levou em conta a estrutura fundiária e produtiva na definição dos limites da Área de Preservação Permanente. A CNA através de sua presidente, a senadora Kátia Abreu, defende a alteração do Código Florestal quanto aos parâmetros para definição de APPs, adotando critérios científicos baseados em laudos geológicos que atestem os riscos de erosão nas proximidades de cursos de água, conforme afirma a senadora.

"Proponho que o artigo $1^{\circ}$ do novo Código Florestal seja explícito e taxativo: "Não será permitida nenhuma derrubada florestal em todo o território nacional, sendo garantida a preservação das matas ciliares (margens dos rios, córregos, nascentes e lagoas) nos limites fixados por laudos geológicos, contra os riscos de erosão e prejuízos aos aquíferos."'”(Abreu, 2009)

A ala ambientalista por sua vez afirma que mesmo não existindo parâmetros com bases cientificas para a delimitação da largura da mata ciliar para cada local, os limites atuais são insuficientes para proteger os cursos de água de processos erosivos e de contaminação por causas antrópicas, como por exemplo a aplicação de agroquímicos ou insumos em lavouras ou pastagens. Para estes, é necessário pelo menos a manutenção dos padrões estabelecidos pelo Código Florestal Brasileiro de 1965, pois através destes parâmetros é possível inclusive se ampliar a área de produção agrícola no país. Em recente estudo, a organização ambientalista WWF BRASIL defende a teoria de que seria possível ao Brasil mais que dobrar a sua área agricultável atual (cerca de 70 milhões de hectares) somente promovendo a recuperação de áreas de pastagens degradadas para o uso agrícola, não sendo necessário assim, avançar sobre APPs ou sobre a Amazônia para viabilizar o avanço econômico do setor agrícola brasileiro.

"Não há dúvidas de que o Brasil é um dos poucos países que ainda dispõe de áreas significativas para a expansão da agricultura. No entanto, ainda é difícil quantificar com exatidão a extensão e a localização destas áreas. 
Muito embora os dados disponíveis na literatura indiquem grandes extensões de terra, ainda não existe um consenso quanto ao número exato. Dessa maneira, dados do IIASA $^{3} / \mathrm{FAO}^{2}$, indicam que o Brasil ainda tenha 187 milhões de hectares aptos a agricultura, ao mesmo tempo em que os dados da $\mathrm{FAO}^{2}$ e do $\mathrm{IBGE}^{8}$, compilados pelo Icone $^{9}$ contabilizam o potencial de área agricultável do Brasil em 133 milhões de hectares, dos quais $77 \%$ resultados da conversão de pastagens e distribuídos em diferentes Estados. Outros trabalhos sugerem que cerca de $30 \%{ }^{10}$ dos aproximadamente 200 milhões de ha de pastagens estejam degradados, o que resultaria em 60 a 70 milhões de ha de áreas abertas que poderiam ser recuperados visando seu uso pela agricultura."(Wwf Brasil, 2009)

Mesmo existindo divergências quanto à extensão da área de expansão agrícola no país, é clara a condição de que existem várias opções para a ampliação da produção agrícola no país, visto que os resultados mais pessimistas apontam para algo entre 60 e 70 milhões de ha disponíveis.

Um olhar mais atento sobre o assunto nos leva a perceber algumas questões relacionadas ao contexto, como por exemplo, a enorme diversidade de condições naturais, econômicas e fundiárias existentes no Brasil. Um país de dimensões continentais, com diferentes processos de apropriação e uso do solo e grande diversidade de aptidão agrícola, seguramente necessita de uma legislação que se adeque a estas condições.

Segundo o IBGE, através do Censo Agropecuário de 2006, os estabelecimentos rurais no Brasil apresentavam um tamanho médio de 68,19 ha, no estado de Goiás o tamanho médio de um estabelecimento rural era de 183,37 ha e no estado de Santa Catarina era de 47,33 ha (Ibge, 2006). O Código Florestal Catarinense foi elaborado levando em conta que devido ao perfil fundiário no estado, a aplicação das regras do Código Florestal Nacional levaria a redução de área agricultável em propriedades com menos de 50 ha de extensão, podendo torná-las inviáveis do ponto de vista econômico. Segundo o Levantamento Agropecuário de Santa Catarina 2003, 90,1 \% dos estabelecimentos agropecuários do estado contavam com menos de 50 ha de área (Lac Santa Catarina, 2003), estando portanto dependentes de tratamento diferenciado na delimitação das APPs.

No estado de Goiás, o tamanho médio de um estabelecimento agropecuário é quase três vezes maior que em Santa Catarina, fato que não traria redução de área significativa ao ponto de inviabilizar a produção agrícola na imensa maioria dos estabelecimentos do estado. Levando-se em conta esta diferença na estrutura fundiária, claramente percebemos que a legislação não deveria ser igual para os dois locais.

O perfil de condições naturais predominantes nos dois estados nos leva também a defender a existência de regras diferenciadas para os dois estados, visto que a cobertura vegetal original, a declividade, a extensão das bacias hidrográficas e as características do solo são diferentes entre eles. $\mathrm{O}$ engessamento dos valores, a determinação de padrões não seria benéfica neste caso.

O Projeto de Lei - PL 5367/2009 - que institui o Código Florestal Brasileiro e estabelece a Política Nacional do Meio Ambiente foi protocoladonaCâmaraFederalnodia03/06/2009, sob autoria do deputado federal Valdir Collato $\mathrm{PMDB} / \mathrm{SC}$ e outros. Este PL traz significativas mudanças nas regras para a determinação de APPs e de outras áreas de proteção, bem como sobre a possibilidade de uso econômico destas 
áreas. Dentre as várias mudanças estabelecidas por este PL, podemos elencar como principais, o estabelecimento de critérios técnicos para a escolha de áreas de proteção e da extensão necessária destas áreas para que elas cumpram sua função através da realização do Zoneamento Econômico Ecológico (ZEE), a determinação da largura da mata ciliar necessária para a efetiva proteção dos cursos d'água, e a possibilidade do uso econômico das áreas de proteção para determinadas finalidades.

O Projeto de Lei 5367/2009 institui que seja realizado em todo o território nacional, o Zoneamento Econômico Ecológico (ZEE) pelos governos estaduais em um prazo máximo de três anos a partir da aprovação da Lei. O ZEE consiste em um estudo detalhado das condições naturais e econômicas do território estadual, levando em conta critérios técnicos e econômicos para definir as áreas que devem ser protegidas.

"Art.45. O Zoneamento Econômico Ecológico (ZEE) tem por objetivo geral a ordenação do território a fim de harmonizar com bases técnicas e cientificas as relações econômicas, sociais e ambientais e nortear, de forma vinculada, as decisões dos agentes públicos e privados quanto a planos, programas, projetos e atividades que, direta ou indiretamente, utilizem recursos naturais."(PL 5367/2009)

O Projeto de Lei determina ainda que podem ser realizados ZEEs em âmbito regional e local por entidades competentes e desde que se garanta a ampla participação das comunidades locais na elaboração do Zoneamento e a concordância com o ZEE estadual. Por sua vez, o governo federal deverá reunir as informações dos ZEEs estaduais e elaborar em um prazo máximo de 180 dias após a elaboração dos ZEEs estaduais, "o ZEE macro do País, tendo como referência o Mapa Integrado dos ZEEs dos Estados." (PL 5367/2009, Art. 52)
O ZEE macro, os estaduais, os regionais e locais servirão como base de dados para a determinação de todas as condições de utilização de recursos naturais no país.

Quanto a demarcação dasáreas deproteção, o PL 5367/2009 determina através dos artigos 74 e 75, que são consideradas áreas de proteção: vegetação ciliar; unidades de conservação; áreas frágeis; e reservas ambientais. Não é estabelecido parâmetro algum sobre a largura das matas ciliares ou o percentual de áreas de reserva, pelo contrário, permite que os ZEEs estaduais ou locais determinem o percentual de área a ser preservada, e que este percentual será alcançado através da soma de todas as áreas de proteção existentes no local. (PL 5367/2009, Art. 74 e 75).

O PL estabelece claramente que são parâmetros técnicos os elementos que devem ser usados na delimitação de matas ciliares ao definir sua função e a quem cabe sua demarcação.

"I - Vegetação ciliar - aquela que ocorre as margens de corpos hídricos, inclusive nascentes, que os protege do assoreamento, retém e filtram impurezas, interceptam e absorvem a radiação solar, preservam a estabilidade geológica e o solo e facilitam o fluxo gênico.” (PL 5367/2009, Art. 74)

“Art. 77. A proteção da vegetação ciliar em cada corpo hídrico e reservatório artificial será determinada pelo órgão ambiental estadual, com base em estudos técnicos e deverá garantir o cumprimento das finalidades descritas em sua definição.” (PL 5367/2009, Art. 77)

Como podemos perceber, se for aprovado, o novo Código Florestal Brasileiro será muito diferente do atual. Enquanto o Código atual determina a largura da mata ciliar de acordo com a largura do espelho d'água, o novo Código 
estabelece o uso de critérios técnicos para tal, e permite que cada estado ou mesmo cada região de estado tenha seus próprios padrões, levando em conta a vegetação natural, o tipo e uso do solo e a erodibilidade do solo como elementos de análise. Além disso, o PL abre possibilidades para a utilização econômica sustentável de áreas protegidas.

\section{CONSIDERAÇÕES FINAIS}

Na prática, o PL 5367/2009 abandona padrões de práticas conservacionistas criadas em circunstâncias bastante diferentes das atuais, pois nele os critérios técnicos passam a ser os elementos responsáveis para a emissão de um parecer a respeito das áreas de preservação. O Código Florestal Brasileiro de 1965 se tornou ultrapassado, visto que para atender as necessidades de proteção a determinadas áreas do país, as medidas e percentuais estabelecidos pela lei poderiam em alguns casos serem insuficientes, e em outros casos serem exagerados, visto que não se baseiam em nenhum estudo com rigor científico para se determinar as áreas necessárias para oferecer proteção a cursos d'água.

Outra questão que emerge no novo contexto é a regionalização dos parâmetros para a proteção. Considerando que o Brasil é um país de dimensões continentais e que apresenta enorme diversidade de condições econômicas, fundiárias e naturais, torna-se praticamente impossível que uma lei padronizada para todo o país atenda, de modo satisfatório, às particularidades de cada região.

Apesar de não agradar completamente a ambientalistas e a ruralistas, o PL 5367/2009, tem o mérito de aproximar a escala de análise de áreas a serem protegidas a níveis mais próximos da realidade de cada local. Desta forma, o país tenta conciliar crescimento econômico e preservação ambiental de áreas importantes para a manutenção da biodiversidade e dos recursos naturais, especialmente os hídricos.
A discussão atual sobre a legalidade do Código Florestal de Santa Catarina tende a se tornar ultrapassada, visto que a aprovação do novo Código Florestal Nacionalautomaticamente concederia aos Estados da Federação a realização do Zoneamento Econômico Ecológico para estabelecer a delimitação das áreas de proteção.

$\mathrm{O}$ novo código tende a se tornar mais aplicável. No entanto, várias questões se colocam frente a esta nova realidade: Os interesses econômicos serão predominantes em relação aos ambientais? Os órgãos ambientais estaduais e locais terão capacidade e isenção para elaborar e aplicar o Zoneamento Econômico Ecológico? Os proprietários rurais terão condições de recompor as áreas degradadas caso o $\mathrm{ZEE}$ detecte esta necessidade?

Como podemos perceber, a aprovação do PL5367/2009 é apenas o primeiro passo para que haja ordenamento legal compatível com a realidade brasileira no uso dos recursos naturais. Neste momento, é impossível assegurar ou mesmo afirmar que com o novo Código Florestal Brasileiro ocorrerá ampliação ou redução da área agricultável, visto que praticamente inexistem estudos técnicos aplicáveis em áreas significativas do Brasil que assegurem a efetiva proteção dos recursos hídricos através da delimitação de matas ciliares.

Os ruralistas, hoje os principais defensores da aprovação do novo Código devem se atentar para o fato de que um local onde hoje a mata ciliar é de 30 metros de largura pode passar a uma metragem maior em função das condições naturais relacionadas ao solo, ao clima, ao relevo e a cobertura vegetal, além das condições antrópicas ligadas ao uso e conservação do solo.

Os ambientalistas, que atualmente tecem críticas ferrenhas a aprovação da nova lei, também devem levar em conta que a lei propõe a adoção de critérios científicos para assegurar a conservação dos recursos hídricos, pois não se trata do estabelecimento de uma metragem 
específica para a largura da mata ciliar, mais da capacidade da vegetação ciliar proteger efetivamente o curso de água ou a nascente de impactos antrópicos.

As mudanças na legislação que agora se processam são fundamentais para garantir a sustentabilidade ambiental no país e a continuidade do crescimento econômico. Conciliar a preservação de recursos naturais ao crescimento econômico é uma tarefa árdua e necessária. O PL 5367/2009 é uma tentativa de realizar esta conciliação. A sua efetiva eficácia ainda é uma incógnita, visto que existem diversas variáveis que podem interferir na aplicação da lei. Seus principais méritos são, sem dúvidas, a possibilidade de regionalização da legislação e o estabelecimento de critérios técnicos científicos na determinação da proteção aos recursos hídricos.

\section{REFERÊNCIAS BIBLIOGRÁFICAS}

ABREU, Kátia. Desmatamento, não. Produção, sim. Canal do Produtor. Disponível em: $<$ http://www.canaldoprodutor.com.br/artigos/ desmatamento-não-produção-sim>. Acessado em 21/07/2009.

BRASIL. IBGE - Instituto Brasileiro de Geografia e Estatística. Censo Agropecuário 2006. Resultados Preliminares. Brasília, 2007. Disponível em <www.ibge.gov.br/.../ agropecuaria/censoagro/2006/agropecuario.pdf >. Acessado em 22/06/2009.

BRASIL. Câmara Federal. Projeto de Lei 5367/2009. Disponível em: <www.camara.gov. br/sileg/integras/667356.pdf $>$. Acessado em 21/07/2009.

BRASIL. Presidência da República. LEI $\mathbf{N}^{0}$ 4.771, DE 15 DE SETEMBRO DE 1965. Disponível em < www.planalto.gov.br/ccivil 03/ LEIS/L4771.htm>. Acessado em 22/06/2009.

SANTA CATARINA. Levantamento Agropecuário de Santa Catarina. Indicadores da evolução do setor agrícola catarinense - Dados preliminares. 2003. Disponível em: <http://www. cidasc.sc.gov.br/agropecuario2/ARTIGO $\% 20$ LAC\%20AGROINDICADOR.pdf $>$. Acessado em 22/07/2009.

SANTA CATARINA. LEI N ${ }^{\mathbf{1}} \mathbf{1 4 . 6 7 5}$, de 13 de abril de 2009. Disponível em <www.sc.gov. br/downloads/Lei_14675.pdf $>$. Acessado em: 20/06/2009.

WWF BRASIL. O impacto do mercado mundial de biocombustíveis na expansão da agricultura brasileira e suas conseqüências para as mudanças climáticas. Programa de agricultura e meio ambiente. Brasília, 2009. 